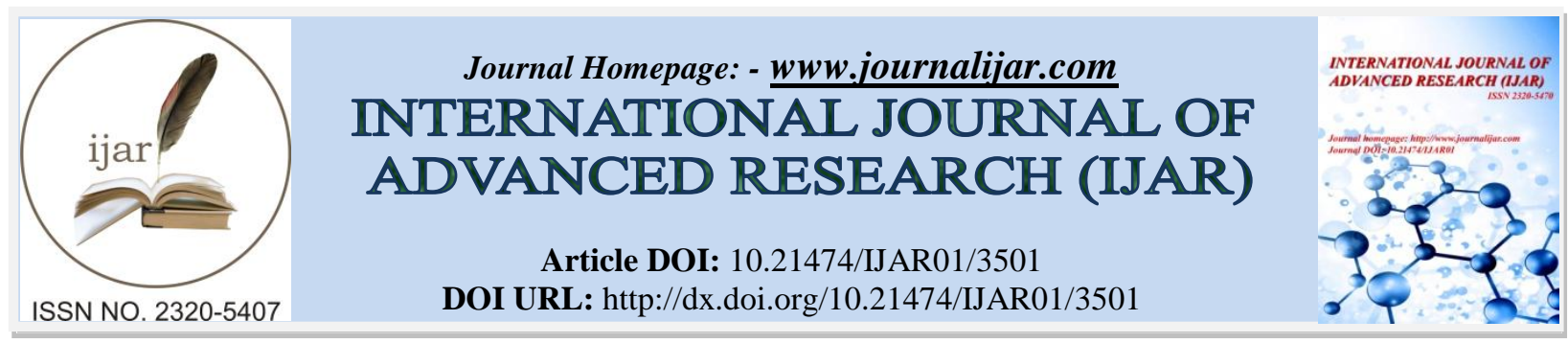

RESEARCH ARTICLE

\title{
PREVALENCE OF DENTINAL HYPERSENSITIVITY IN DAKSHINA KANNADA POPULATION
}

\author{
Dr. Sreenath $\mathbf{N}^{1^{*}}$, Prof. Dr. Mithra N. Hegde ${ }^{2}$ and Dr. Mahalakshmi Yelapure ${ }^{3}$
}

1. Post graduate student, Department of Conservative Dentistry and Endodontics, A. B. Shetty Memorial Institute of Dental Sciences, Nitte University, Deralakatte, Mangaluru

2. Vice Principal, Dean of Dental Faculty, Head of the Department of Conservative Dentistry and Endodontics, A. B. Shetty Memorial Institute of Dental Sciences, Nitte University, Deralakatte, Mangaluru

3. Reader, Department of Conservative Dentistry and Endodonitcs, A. B. Shetty Memorial Institute of Dental Sciences, Nitte University, Deralakatte, Mangaluru

\section{Manuscript Info}

Manuscript History

Received: 15 January 2017

Final Accepted: 16 February 2017

Published: March 2017

Key words:-

Dentine hypersensitivity, Dakshina

Kannada.

\begin{abstract}
The aim of the survey was to study the prevalence, common causes, aggravating factors and awareness about dentine hypersensitivity in urban and rural patients of Dakshina Kannada population. A total of 1000 patients were randomly selected, who reported at the A. B. Shetty Memorial Institute of Dental Sciences, Nitte University and Satellite Rural Centres. Dentine hypersensitivity was evaluated by questionnaire, oral and clinical examination. On analysis of data, it was found that the prevalence of dentine hypersensitivity was $19.2 \%$. Cold was the most common (68.2\%) aggravating factor and the most common cause was gingival recession (47.9\%), followed by caries (24\%). Most common age group affected by dentine hypersensitivity was between 21-30. It was also noted that population had limited awareness about the causes, symptoms and treatment modalities of dentine hypersensitivity.
\end{abstract}

Copy Right, IJAR, 2017,. All rights reserved.

\section{Introduction:-}

Dentine hypersensitivity (DH) has been defined as a short, sharp pain arising from exposed dentine as a response to stimuli typically thermal, evaporative, tactile, osmotic or chemical and which cannot be ascribed to any other form of dental defect, disease or pathology $[1,2]$. DH is a very common condition that is frequently encountered in clinical dental practice. It is a clinical condition in permanent teeth caused by dentin exposure to the oral environment as a consequence of loss of enamel and/ or cementum [3]. Several theories have been proposed to explain the mechanism of dentine sensitivity. Of these the most widely accepted theory is called hydrodynamic theory of sensitivity. This theory postulates that rapid shift in either direction of the fluid within the dentinal tubules following stimulus application, results in activation of sensory nerves in the pulp/inner dentine region of the tooth $[4,5]$. Several studies indicate that $\mathrm{DH}$ was found in adult populations, with prevalence of more than $40 \%$ worldwide, 4 to $74 \%$ in India and $26 \%$ in southern India [6]. The rural population may have a lot of barriers preventing them to attend the dental clinics/institutes which are mainly situated in urban settings. A number of people with mild tooth sensitivity do not visit the dentist. Therefore, it may be difficult to get the actual prevalence of dentine hypersensitivity in the population. Patients usually do not report this painful condition to their dental practitioners and when they do, they report experiencing sharp pain after a number of stimuli's [7]. DH may occur also as a result of history of any dental treatment as well. DH may even result in emotional changes that alter

Corresponding Author:- Dr. Sreenath N.

Address:- Post graduate student, Department of Conservative Dentistry and Endodontics, A. B. Shetty Memorial Institute of Dental Sciences, Nitte University, Deralakatte, Mangaluru 
behaviour, in extreme cases [8]. The purpose of this cross sectional study was to evaluate the prevalence, common causes, aggravating factors, association with previous dental treatment and patients' awareness about dentine hypersensitivity among the urban and rural patients of Dakshina Kannada population.

\section{Materials and Methodology:-}

The study was conducted on a total of 1000 patients over a period of 3 months from June to August 2016, after obtaining written consent, out of which 500 were examined from the Out-Patient section of Department of Conservative Dentistry and Endodontics and rest 500 were examined in Satellite Rural Centres of A. B. Shetty Memorial Institute of Dental Sciences, Nitte University, Deralakatte, Mangaluru.

\section{Inclusion criteria:-}

- Patients between the age of 15-70 years

- History of dentine hypersensitivity

\section{Exclusion criteria:-}

- Teeth with prosthodontic crowns

- Patients consuming analgesic drugs, anti-psychotic drugs or mood altering medications

Data obtained was entered in M S Excel spreadsheet and statistical analysis was done using the Statistical Package for the Social Sciences (SPSS 22). Difference between variables were analyzed using Pearson Chi-Square test.

\section{Results:-}

Out of 1000 patients, 192 patients showed a positive response to dentine hypersensitivity (prevalence is 19.2\%). The prevalence was highest in the age group of 21-30 years (32.3\%) [Fig.2]. Males (59.9\%) were more affected than females (40.1\%) [Fig.1]. Most common aggravating factors for DH is cold (68.2\%), followed by sweet (27.6\%) and hot (4.2\%) [Table.1]. Most common causes found were gingival recession (47.9\%), caries $(24.0 \%)$, and tooth abrasion (19.8\%) [Fig.3]. Out of the 192 cases that presented hypersensitivity, 75 cases (39.1\%) had history of regular soft drinks consumption ( $\mathrm{p}=0.013$ ). Out of 1000 patients, only 38 cases reported of any recent history of dental treatment and $39.4 \%$ of them had undergone oral prophylaxis/root planing, 36.8\% underwent orthodontic treatment including proximal stripping.

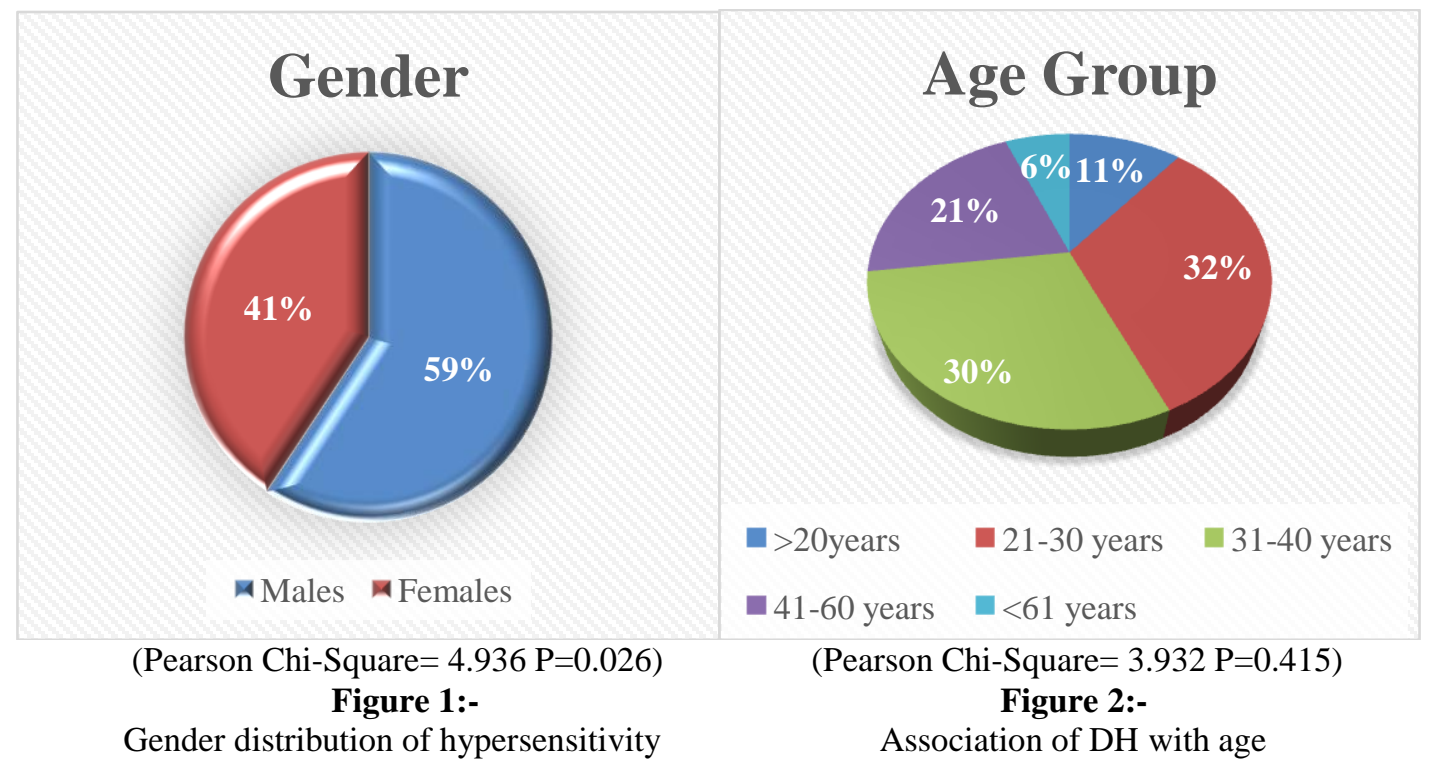




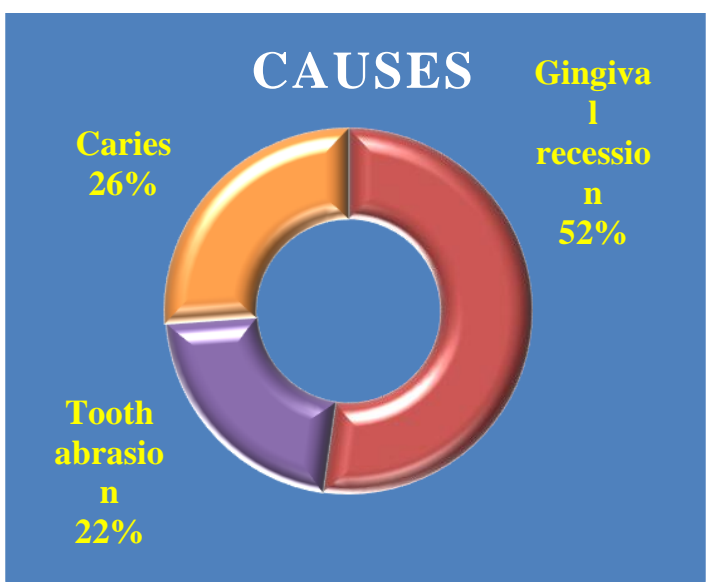

Figure 3:- Causes of DH.

Table 1:- Aggravating factors of DH.

\begin{tabular}{|c|c|c|}
\hline Factors & Frequency & Percent \\
\hline Hot & 8 & 4.1 \\
\hline Cold & 131 & 68.2 \\
\hline Sweet & 53 & 27.6 \\
\hline Total & 192 & 100.0 \\
\hline
\end{tabular}

\section{Discussion:-}

According to the results of the questionnaire and clinical examination, the present study showed that the prevalence of dentine hypersensitivity was overall $19.2 \%$, which is similar to the previous study done by the Hegde et al $22.5 \%$; [9] and Dhaliwal et al 25\% [10]. Some studies that have been carried out with questionnaires had reported values of more than $50 \%$ or less than $20 \%$ [11, 16]. There are studies from dental practices which have reported prevalence values from $4-15 \%[12,19]$. The differences may be due to the type of sample and methods used in the studies. It could also be due to the variation in the geographical locations with different dietary habits and oral hygiene practices.

In the present study, dentine hypersensitivity is more prevalent in males than females as against studies done by Rees JS, Addy M [13], Hsin Cheng Liu [14] and N A Chrysanthakopoulos [15] which may be due to their overall healthcare and better oral hygiene awareness while the study done by Chabanski M B [17] is in accordance with this study.

In the present study dentine hypersensitivity is more prevalent in age group of 21-30 years and least above the age of 60. This particular age distribution may be because of more frequent and aggressive oral hygiene regimen adopted. A reduction of DH in seniors could be plausible due to the development of secondary or reparative dentine and subsequent sclerosis of the dentinal tubules accompanied by reduced sensitivity. Maxillary teeth seem to be more affected that mandibular teeth with 122 of the 192 patients affected by hypersensitivity complaining of the same in maxillary teeth compared to the 70 others who had hypersensitivity in the mandibular teeth. This is in accordance with study done by Addy $\mathrm{M}$ et al [18].

Several possible etiologic and predisposing factors for dentine hypersensitivity have been proposed [19]. In this study, gingival recession was seen to be the leading cause of dentinal hypersensitivity (52\%). Dentine tubules may become exposed as a result of enamel loss from attrition, abrasion, erosion (acid dissolution) or abfraction (cervical stress lesion) [20], but dentin exposure often may be a result of gingival recession and cementum loss from root surfaces, most frequently in canines and premolars [21]. Aggressive or frequent tooth brushing [22] and periodontal treatment (such as scaling and root planning [23] could also result in elevating DH.

Soft drinks had a direct association with dentine hypersensitivity in the present study, with $39.1 \%$ of the positive respondents to DH having a habit of regular consumption of soft drinks. The study had similar findings with Colak et al study among students in Turkey [8]. Soft drinks are carbonated that leads to tooth wear by erosion of enamel 
surface and then dentine, leading to DH. According to studies done by S. Wongkhantee [24], ME Barbour [25] and Vanuspong $\mathrm{W}$ [26], acidic beverages and cola drinks depending on $\mathrm{pH}$, temperature and frequency of exposure are responsible for softening of dental hard tissues and restorative materials that are exposed.

Cold was the most common factor which initiated the pain as experienced by most of the patients (68.2\%). This result was similar to the studies done by Rees JS et al \& Tan CS et al [27]. Sweet stimulus was the second most common aggravating factor(27.6\%), which was in accordance with study done by J.S Dhaliwal et al [10] but not in agreement with studies done by Fischer et al [3], Rees JS et al [13], Flynn J et al [28] where heat was found to be the second most common aggravating factor for DH as pain from heat takes longer to develop than pain from cold, because heat causes inward movement of tubular fluid while the outward movement caused by cold develops more rapidly.

\section{Conclusion:-}

The prevalence of dentinal hypersensitivity among Dakshina Kannada population is $19.2 \%$. Dentine hypersensitivity is a clinically relevant and worldwide problem that may affect about a quarter of the adult population. Even though dentine hypersensitivity may not be considered a fatal or severe problem, it affects the quality of life of patients and, therefore, it should be properly addressed in research, dental education, prevention, and treatment.

\section{References:-}

1. Addy M, Urquhart E. Dentine hypersensitivity: its prevalence, aetiology and clinical management. Dent Update 1992; 19: 407-408, 410-412.

2. Rees JS, Jin LJ, Lam S, Kundanoswaka I, Vowles R. The prevalence of dentine hypersensitivity in a hospital clinic population in Hong Kong. J Dent 2003;31: 453-461.

3. Fischer C, Fischer RG, Wennberg A. Prevalence and distribution of cervical dentine hypersensitivity in a population in Rio de Janeiro, Brazil. J Dent1992; 20: 272-276.

4. Dalzabneh RH, Khouri AT, Addy M. Dentin hypersensitivity- an enigma. A review of terminology, mechanism, aetiology and management. Br Dent J 1999;187:606-11

5. Gysi A. An attempt to explain the senstitiveness of dentin. Br Dent J 1900;20:272-6

6. Mithra N. Hegde, Neha Bhalla. The prevalence of Dentine Hypersensitivity in Southern India. JIDA Vol. 3, No. 6, June 2009; 189-91

7. Kim JL, Karastathis D. Dentinal hypersensitivity management. In: Darby ML, Walsh MM. Dental Hygiene Theory and Practice, 3rd ed. St. Louis, MO: Saunders-Elsevier; 2010.q726-35.

8. Colak H, Aylıke BU, Hamidi MM, Uzgur R. Prevalence of dentine hyper-sensitivity among university students in Turkey. Nigerian J Clin Pract 2012;15(4):415-9.

9. Sonal S Dhodiya, Mithra N Hegde. A Cross-Sectional Study Of Dentin Hypersensitivity in South Kanara Population: Indian Journal Of Applied Research 2014; Vol 4: Issue 6

10. Dhaliwal JS, Palwankar P, Khinda PK, Sodhi SK. Prevalence of dentine hypersensitivity: A cross-sectional study in rural Punjabi Indians. Journal of Indian Society of Periodontology. 2012 Jul 1;16(3):426.

11. Murray LE, Roberts AJ. The prevalence of self reported hypersensitive teeth. Arch Oral Biol. 1994;39:129S$35 \mathrm{~S}$.

12. Irwin CR, McCusker P. Prevalence of dentine hypersensitivity in a general dental population. J Ir Dent Assoc. 1997;43:7-9.

13. Rees JS, Addy M. a cross-sectional study of dentine hypersensitivity. j clin periodontology 2002; 29: 997-1003.

14. Hsin - Cheng Liu, Wan - Hong Lan and Chi - Chuan Hsieh: Prevalence and Distribution of cervical dentin hypersensitivity in a population in Taipei, Taiwan. J. of Endo January 1998: 23(1),45-47.

15. N.A. Chrysanthakopoulos Prevalence of Dentine Hypersensitivity in a General Dental Practice in Greece. J Clin Exp Dent. 2011;3(5): e445-51.

16. Gillam DG, Aris A, Bulman JS, Newman HN, Ley F. Dentine hypersensitivity in subjects recruited for clinical trials: clinical evaluation, prevalence and intra-oral distribution. J Oral Rehabil. 2002;29:226-31.

17. Chabanski M B, Gillam DG, Bulman JS, Newman HN: prevalence of cervical dentine hypersensitivity in a population of patients referred to a specialist Periodontology Department, J Clin Periodontology 1996; 23: 989992.

18. Addy M, Pearce N. Aetiological, predisposing and environmental factors in dentine hypersensitivity. Archs Oral Biol. 1994;39:33-38. 
19. Pashley DH, Tay FR, Haywood VB, Collins MA, Drisko CL. Consensus-based recommendations for the diagnosis and management of dentin hypersensitivity. Inside Dent. 2008;4(9 special issue):1-37.

20. Smith BG, Knight JK. A comparison of patterns of tooth wear with aetiological factors. Br Dent J. 1984;157(1):16-19.

21. Orchardson R, Collins WJ. Clinical features of hypersensitive teeth. Br Dent J. 1987;162(7):253-256.

22. Khocht A, Simon G, Person P, Denepitiya JL. Gingival recession in relation to history of hard toothbrush use. J Periodontol. 1993;64(9):900-905.

23. Chabanski MB, Gillam DG, Bulman JS, Newman HN. Clinical evaluation of cervical dentine sensitivity in a population of patients referred to a specialist periodontology department: a pilot study. J Oral Rehabil. 1997;24(9):666-672.

24. S. Wongkhantee, V. Patanapiradej, C. Maneenut, D. Tantbirojn. J. of Dentistry 2006; 34, 214-20.

25. M.E. Barbour, M. Finke, D.M. Parker, J.A. Huges, G.C. Allen, M. Addy. J. of Dentistry 2006; 34, 207-13.

26. Vanuspong W, Eisenburger M, Addy M : Cervical tooth wear and sensitivity: erosion, softening and rehardening of dentine; effects of $\mathrm{pH}$, time and ultrasonication. J Clin. Periodontal 2002; 29: 351-57.

27. Tan CS, Hu DY, Fan X, Li X, Que KH. Epidemiological survey of dentine hypersensitivity of young people in Chengdu City. West China journal of stomatology. 2009 Aug;27(4):394-6.

28. Flynn J, Galloway R, Orchardson R. The incidence of hypersensitive teeth in the west of Scotland. J Dent. 1985;13:230-6. 